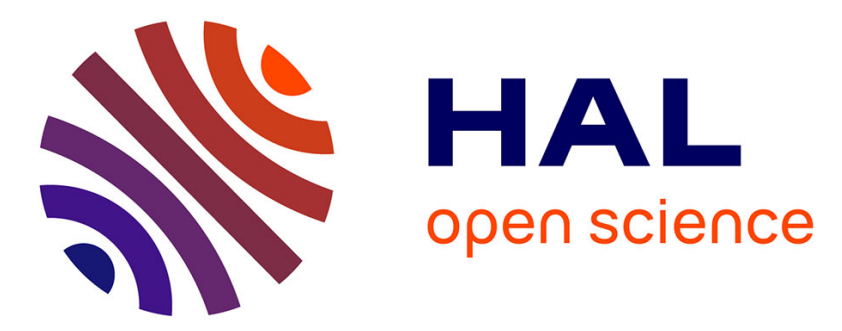

\title{
Evolution of electromyographic signal, running economy, and perceived exertion during different prolonged exercises
}

Christophe Hausswirth, Jeanick Brisswalter, Jean-Marc Vallier, D. Smith, R. Lepers

\section{To cite this version:}

Christophe Hausswirth, Jeanick Brisswalter, Jean-Marc Vallier, D. Smith, R. Lepers. Evolution of electromyographic signal, running economy, and perceived exertion during different prolonged exercises. International Journal of Sports Medicine, 2000, 21 (6), pp.429-436. 10.1055/s-2000-3832 . hal-01823707

\section{HAL Id: hal-01823707 https://hal-insep.archives-ouvertes.fr/hal-01823707}

Submitted on 26 Jun 2018

HAL is a multi-disciplinary open access archive for the deposit and dissemination of scientific research documents, whether they are published or not. The documents may come from teaching and research institutions in France or abroad, or from public or private research centers.
L'archive ouverte pluridisciplinaire HAL, est destinée au dépôt et à la diffusion de documents scientifiques de niveau recherche, publiés ou non, émanant des établissements d'enseignement et de recherche français ou étrangers, des laboratoires publics ou privés. 


\title{
Evolution of electromyographic signal, running economy, and perceived exertion during different prolonged exercises
}

\author{
C. Hausswirth ${ }^{1}$, J. Brisswalter ${ }^{2}$, J. M. Vallier $^{3}$, D. Smith ${ }^{4}$, R. Lepers ${ }^{5}$ \\ ${ }^{1}$ Laboratoire de Biomécanique et de Physiologie, Institut National du Sport et de l'Education Physique, \\ Paris, France \\ ${ }^{2}$ Université de Toulon-Var, Unité Ergonomie Sportive et Performance, La Garde cedex, France \\ ${ }^{3}$ Département médical, Institut National du Sport et de l'Education Physique, Paris, France \\ ${ }^{4}$ Consultant Sport Scientist, Gold Coast, Queensland, Australia \\ ${ }^{5}$ Université de Bourgogne, Groupe d'Analyse du Mouvement, UFR-STAPS, Campus universitaire, \\ Dijon cedex, France
}

Corresponding Author: C. Hausswirth, Ph. D. Institut National du Sport et de L'Education Physique Laboratoire de Biomécanique et de Physiologie 11, avenue du Tremblay 75012 Paris France - Phone: + 33 (1) 41744385 Fax: + 33 (1) 41744535 E-mail: christophe.hausswirth@wanadoo.fr

Article publié dans : International journal of sports medicine, 2000, vol.21, $n^{\circ} 6, p p .429-436$

\begin{abstract}
The purpose of this study was to compare the electromyographic (EMG) signal of the vastus lateralis muscle obtained during a run section of a triathlon and at the end of a prolonged run performed at the same running velocity. Seven subjects were studied on three occasions: a 2 h 15 min triathlon (30 min swimming, 60 min cycling, and 45 min treadmill running at $75 \%$ of the maximal aerobic speed), a $2 \mathrm{~h}$ 15 min run, where the last 45 min (Prolonged Run, PR) were run at the same speed as the Triathlon Run (TR) on a motorized treadmill, and a 45 min Isolated Run (IR) performed at the same TR and PR velocity. The three experimental trials were randomised. Oxygen uptake $\left(\mathrm{VO}_{2}\right)$, heart rate (HR), and EMG data were recorded during the three run sections. The results confirm a greater $\mathrm{VO}_{2}$ and $\mathrm{HR}$ during PR compared with IR $(\mathrm{P}<0.01)$ and TR $(\mathrm{P}<0.05)$. Also the $\mathrm{VO}_{2}$ values obtained during TR were significantly greater compared to IR ( $\mathrm{P}<0.05)$. EMG signal, obtained from the vastus lateralis muscle during $4 \mathrm{sec}$ of isometric contraction at $35 \%$ of maximal voluntary contraction (MVC), showed that after PR the mean power frequency (MPF) shifted significantly to lower frequencies $(\mathrm{P}<0.01)$ compared with MPF recorded before the prolonged run. Moreover, the signal amplitude (RMS) was increased significantly after $\mathrm{PR}$ in comparison to pre-trial $(\mathrm{P}<0.01)$. Similar resuits were obtained for the TR at $\mathrm{P}<0.05$. The integrated EMG flow, QIEMG (iEMG/burst duration), recorded during all run sections, was significantly increased near the end of PR (i.e. 2 h 10 min of running) compared with QiEMG recorded after 1 h 30 min of running. No significant increase in QiEMG was observed with TR and IR situations. The results suggest that a long exercise bout of running led to a greater increase in muscle fatigue compared with a triathlon or an isolated run performed at the same running speed. In addition it is suggested that the rating of perceived exertion recorded during isometric contractions is a good indice to approach the level of fatigue during prolonged exercices.
\end{abstract}

Key words: Triathlon, prolonged run, oxygen uptake, muscle fatigue, myoelectric power spectrum. 


\section{Introduction}

While the popularity of triathlon events has increased over the past five years, limited information is available concerning the physiological responses of the triathlete occurring during the run section that follows swimming and cycling sections [14,15, 21]. Typically during a triathlon, involving consecutive trials in swimming, cycling, and running, the musculature of the upper and lower body is utilized for the three different events. In regard to the influence of cycling on the running performance, the first data recorded by Boone and Kreider [41 have demonstrated that the energy cost of running (Ec) was higher when it was carried out after a warm-up on the ergocycle than when it was performed after a warm-up on the treadmill. In addition to this result Kreider et al. [21] showed that at the end of a simulated triathlon conducted in a laboratory both oxygen uptake and heart rate values were greater during a $10 \mathrm{~km}$ triathlon run than during a control run. More recently this result was confirmed by Guézennec et al. [141 during an overground simulated triathlon: these authors have shown a decrease of running efficiency during the run section of the triathlon compared with an isolated run performed at the same pace.

Analysis of surface electromyographic (SEMG) activity has been used increasingly in order to study muscle fatigue [8]. It has been found that an increase in EMG amplitude with time has been associated with prolonged submaximal muscle contractions [1 ]. Although the mechanisms of these alterations are debatable, changes in the myoelectric signais have been shown to provide information relating to events which occur inside the muscle [8]. Relationships have been found recently between running economy and temporal EMG characteristics of leg muscles [17], however no data is available concerning running economy and the modifications of integrated EMG records obtained at the end of prolonged exercise of running.

While several studies have reported an increase in the energy cost of running at the end of a triathlon compared to a control run performed at the same speed [14,15], few studies have attempted to compare the evolution of the Ec obtained during the triathlon run and the Ec recorded at the end of a marathon run performed at the same velocity $[15,16]$. The foregoing studies confirmed the decrease in running efficiency previously shown during the run section of a triathlon and demonstrated that this decrease was less than that observed during the final phase of a marathon. However, the relationships between EMG signal and the appearance of muscle fatigue due to different types of prolonged exercise have not been yet documented.

The aims of the present study were therefore to:

1. verify the decrease in running economy previously observed during both a triathlon and a prolonged run,

2. compare the evolution of the integrated electromyographic flow obtained during a run section of a triathlon and at the end of a prolonged run performed at the same running speed,

3. to determine EMG changes recorded during isometric contractions at the end of each prolonged exercise (triathlon, prolonged run) and correlate these changes with the fatigue level.

\section{Methods}

\section{Subjects}

The subjects who participated in this study were seven well-motivated male triathletes. They were comprehensively informed of the requirements and procedures of the experiment. The subjects were selected on the basis of their performance time over the 'Olympic' distance triathlon (range $1 \mathrm{~h} 57-2 \mathrm{~h}$ 27). A briefing session was conducted in order to familiarize subjects with the cycling circuit and treadmill which were to be used during the investigation. The subjects completed a light training program during the recovery period of each testing session. During the entire experimental procedure the subjects were to not perform any exhausting exercise in the 48 hours preceding each test. The anthropometric data and physiological characteristics of the subjects are reported in Table 1 . These 
data are similar to those reported in previous studies $[21,30]$.

\section{Maximal oxygen uptake ( $\left.\mathrm{VO}_{2} \mathrm{max}\right)$ and oxygen uptake measurements}

1) Subjects initially performed a running $\mathrm{VO}_{2}$ max test on a motorized treadmill fixed at $0 \%$ gradient (2500 ST, GYMROL, Andrezieux-Boutheon, France). The test began with a warm-up at $12 \mathrm{~km} \mathrm{x} \mathrm{h}^{-1}$ for $9 \mathrm{~min}$, and the running speed was then increased by $1 \mathrm{~km} \mathrm{x} \mathrm{h}^{-1}$ every 2 min until volitional exhaustion. Oxygen uptake was recorded continuously with a metabolic cart measurement (type CPX, Medical Graphics, Saint-Paul, Minnesota, USA). The criteria used for the determination of $\mathrm{VO}_{2}$ max were: a plateau in $\mathrm{VO}_{2}$ despite an increase in running speed, a Respiratory Exchange Ratio (RER) above 1.1, and a heart rate (HR) over $90 \%$ of the predicted maximal HR [2]. The Maximal Aerobic Speed (MAS) was the highest speed completed for 2 minutes.

2) Oxygen uptake $\left(\mathrm{VO}_{2}\right)$ was recorded using the $\mathrm{CPX}$ analyser. $\mathrm{VO}_{2}$ values collected during the treadmill sessions were recorded as previously reported [15], i.e. during the second to fifth minute of running $(2-5$, period 1$)$, during the fifteenth to twenty-second $\min (15-22$, period 2$)$, and the thirtyfifth to fourty-second min $(35-42$, period 3$)$ in order to give the runners a maximum of respiratory comfort and let them drink during the treadmill run (Fig. 1). The calculation of the energy cost of running $(\mathrm{Ec})$ is usually performed using the formula given by Di Prampero [9]:

$$
\mathrm{EC}\left(\mathrm{ml} \text { of } \mathrm{O}_{2} \times \mathrm{min}^{-1} \times \mathrm{km}^{-1}\right)=\frac{\dot{\mathrm{vO}} \mathrm{O}_{2}\left(\mathrm{ml} \mathrm{of}_{2} \times \mathrm{min}^{-1} \times \mathrm{kg}^{-1}\right)-0.083}{\text { Speed }\left(\mathrm{km}^{-1} \mathrm{~h}^{-1}\right)} \times 60
$$

The 0.083 (in $\mathrm{ml} \mathrm{x} \mathrm{kg}^{-1} \mathrm{x} \mathrm{s}^{-1}$ ) is $\mathrm{VO}_{2}$ value corresponding to the y-intercept of the $\mathrm{V0}_{2}$-speed relationship established in young male adults [25].

Head rate was monitored using a cardiofrequency meter (BHL-6000, Bauman-Haldi SA, Fleurier, Switzerland).

\section{Protocol and experimental procedures}

The experimental trials (the first, second, and third testing sessions) were randomized for each subject in order to avoid problems due to a Jack of motivation or motor skills learning. Moreover, to secure a complete recovery, the delay between each test was about one week for each triathlete. The protocol is presented in Fig. 1: it was the same previously applied by Hausswirth et al. [16]. Each triathlete carried out the proposed trials as if it was a real competition in spite of the absence of a direct competitor. All triathletes performed an isolated run (IR) test of 45 minutes at $75 \%$ of the Maximal Aerobic Speed (MAS) recorded during the $\mathrm{VO}_{2}$ max test. The second testing session was the simulation of a triathlon of $2 \mathrm{~h} 5$ min duration. It consisted of 30 min swimming, 60 min cycling on a flat traffic-free road, and 45 min treadmill running ( $0 \%$ gradient) at $75 \%$ of MAS. For the cycling trial the triathletes had to maintain the pedalling frequency obtained after $10 \mathrm{~min}$ of cycling $( \pm 2 \mathrm{rpm})$ and were allowed to change gear when they liked. The two transition times between the 3 events of the triathlon were slightly greater compared to those usually recorded in competition. The change over time between swimming-cycling was about $3 \mathrm{~min}$ and $2 \mathrm{~min}$ for the cycling-running transition, including the time needed to place the three EMG electrodes and change shoes. The third testing session was termed 'Prolonged run' consisting of the achievement of a $2 \mathrm{~h} 15 \mathrm{~min}$ exercise bout of running. The subjects ran first for $1 \mathrm{~h} 30 \mathrm{~min}$ on a flat track: they had to run at $80-85 \%$ of their maximum heart rate value during this period. The outdoor-laboratory transition was about 2 min, including the time needed to place the three EMG electrodes. During the last 45 min of the Prolonged Run (PR) performed on the treadmill ( $0 \%$ gradient), speed was identical to that performed during the Triathlon Run (TR) and the Isolated Run (IR). A photocell arrangement was mounted at the far end of the treadmill. Thus the time between photocell pulses was combined with measured treadmill belt length assuming the adjustment of the instantaneous running speed.

Outside air temperatures ranged from 18 to $27^{\circ} \mathrm{C}$ while the laboratory temperature ranged between 23 
$-25{ }^{\circ} \mathrm{C}$. The weather conditions were similar (no wind) during both triathlon and marathon. During all run sections on the treadmill two fans were placed in front of the runners. Each triathlete ingested one liter of water at their disgression during each testing session. The mean swimming distance was $1580 \pm$ $407 \mathrm{~m}\left(3.1 \mathrm{~km} \mathrm{x} \mathrm{h}^{-1}\right)$, cycling distance $36.2 \pm 2.2 \mathrm{~km}\left(36.2 \mathrm{~km} \mathrm{x} \mathrm{h}^{-1}\right)$, and running distance $10.8 \pm 1.5$ $\mathrm{km}\left(13.8 \mathrm{~km} \mathrm{x} \mathrm{h}^{-1}\right)$.

\section{Muscle tests}

\section{Isometric contractions}

Right isometric knee extensions were performed using an isometric ergometer (type: J. Schnell, Selephon, Germany). Before each testing session the subjects were asked to perform maximal isometric contraction of short duration $(2-3 \mathrm{sec})$ of the knee extensors muscles. The maximal force at a knee angle of $80^{\circ}$ was measured, and the best performance after four trials was selected as maximal voluntary contraction at $80^{\circ}\left(\mathrm{MVC}_{80}\right)$. Approximately $2-3$ min separated each of the four trials. After a 10 min warm-up on the treadmill at $60 \%$ of their MAS, subjects maintained an isometric contraction of the knee extensor muscles at $35 \% \mathrm{MVC}_{80}$ for $4 \mathrm{sec}$. The required force of contraction was displayed by an oscilloscope placed in front of the subject. We have taken into consideration only the 3 last sec of the contraction for the analysis of EMG data; the first second was considered as the time to reach the reference line of $35 \% \mathrm{MVC}_{80}$ showed on the oscilloscope and was therefore not analyzed. The mean value of the $3 \mathrm{sec}$ analyzed was called non-fatigued (NFO) value. Also recorded was a $4 \mathrm{sec}$ isometric contraction during the treadmill run of each event (Triathlon Run, TR; Prolonged Run, MR; Isolated Run, IR); the isometric ergometer was placed next to the treadmill. The times of measurement were precisely at the fifth min (TR1, PR1 and IR1 ), the $22 \mathrm{~min}$ (TR2, PR2, and 1R2), and the $45 \mathrm{~min}$ (TR3, PR3, and IR3) of running.

During all isometric contractions subjects were in a sitting position, securely strapped into the muscletest chair. The seated posture met the following specifications: hip angle $10^{\circ}$, knee angle $80^{\circ}$. Before and after each trial subjects had to indicate the perceived exertion value according to the Borg's scale DP 20 [5]; all values were recorded immediately after the $4 \mathrm{sec}$ of knee extension.

\section{Dynamic contractions}

During the treadmill run the EMG activity was recorded during the second to fifth min of running (2 5), during the seventeenth to twentieth $\min (17-20)$, and the thirty-ninth to forty-second min $(39-42)$. During both isometric (i.e. knee extension) and dynamic contractions (i.e. treadmill run) the EMG activity of the vastus lateralis muscle was recorded by means of bipolar, silver/silver chloride, surface electrodes (interelectrode distance $=20 \mathrm{~mm}$; area of electrode $50 \mathrm{~mm}^{2}$ ) positioned over the belly of the muscle contracted. The skin was prepared by surface abrasion, cleaned with $33 \%$ ether, $33 \%$ aceton, $33 \%$ alcohol. The impedance was checked, and only values below $5 \mathrm{k} \Omega$ were accepted. The two electrodes were fixed lengthwise over the motor point (approximately $20 \mathrm{~cm}$ above the knee). To be sure that electrodes were precisely at the same place for each testing session, we marked the electrode location on the skin with an indelible marker. The electrodes were secured with surgical tape and cloth wrap, and electrode wires were also secured to an elastic belt worn by subjects to minimize disruption during the movement. The electrode housing contained a solid state preamplifier (signal amplified 35 times), and the preamplified signal was subsequently amplified (gain setting of 10 which includes preamplification). After amplification (x 600) the signal was recorded on a SONY tape recorder type KMT (SONY Corporation, GmbH Kraus-Messtechnik, Otterfing, Germany, banwidth from 6 to 1500 $\mathrm{Hz}$ ) and stored on a digital audio tape. The sampling rate was $12 \mathrm{kHz}$ per channel with 12 bit data resolution. Off-line EMG recorded samples were digitized using a $1 \mathrm{kHz}$ sampling rate and stored on a computer disk: the EMG was then processed. 
For the isometric contractions the power spectrum density function of each recording was calculated by fast Fourier transformation. The analyser computed a mean spectrum by calculating the root mean square (RMS) values obtained from consecutive time windows of $0.5 \mathrm{~s}$ duration. The resulting spectrum was defined by 512 points in amplitude and phase. The final result of this signal analysis was a number of EMG variables including RMS and the frequency of the mean power frequency (MPF). It was calculated according to the equation given by Kwatny et al. [22]. A comparison was done systematically between the isometric EMG data recorded before and during each running test (3 periods of time). For the dynamic contractions integrated EMG values (iEMG) were calculated during the final 2 min of each 3 min recording segment (Dynaview 1.0, G. Dietrich, Paris, 1995). In order to analyze a same session during the three runs, 10 consecutive running bursts during the foot contact phase were integrated at $1 \mathrm{~min}$ and $2 \mathrm{~min}$ (period 1), $19 \mathrm{~min}$ and $20 \mathrm{~min}($ period 2), $41 \mathrm{~min}$ and $42 \mathrm{~min}$ (period 3). We normalized all iEMG values expressed with regard to the burst duration (iEMG/burst duration) obtained in a non-fatigue state: these values were considered as the measurement of muscle activity. These values were named 'iEMG flow, QiEMG'.

\section{Statistical analysis}

The global statistical analysis of all studied parameters in relation to the various moments and types of exercise identified (Triathlon Run [TR], Marathon Run [PR], Isolated Run [IR]) was performed by means of a two-way analysis of variance, ANOVA $(2 \times 3)$. The comparison of variables between the experimental conditions was conducted with Student's t-test for paired samples. All values are expressed as mean standard deviation (SD). For all statistical tests the level of significance was set at $\mathrm{P}$ $<0.05$.

\section{Results}

\section{Oxygen uptake and energy cost of running}

The variance analysis demonstrated a global effect of the exercise $(\mathrm{P}<0.05)$ on $\mathrm{V}_{2}$ values. In comparison with the TR and IR the PR showed a greater $\mathrm{VO}_{2}$ throughout the trial. For Ti (2 - 5), T2 $(15-22)$, and $\mathrm{T} 3(35-42)$ the $\mathrm{VO}_{2}$ values obtained during the triathlon were higher than those measured during IR $(\mathrm{P}<0.05)$. The initial values for TR1, PR1, and IR1 were $50.6 \mathrm{ml} \mathrm{x} \mathrm{min}^{-1} \mathrm{x} \mathrm{kg}^{-1}$,

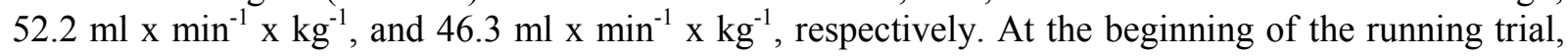
$\mathrm{VO}_{2}$ was higher during PR than during both TR and IR $(+3 \%, \mathrm{P}<0.05$ and $+11 \%, \mathrm{P}<0.01$, respectively). At the end of the running trial $\mathrm{VO}_{2}$ was higher during PR than during both TR and IR (+ $3 \%, \mathrm{P}<0.05$ and $+10 \%, \mathrm{P}<0.01$, respectively). Table 2 shows the changes in the energy cost of running (Ec) in relation to the 45 min running under PR, TR, and IR conditions. TR and PR led to a greater Ec throughout the running test in comparison with IR values $(\mathrm{P}<0.01)$. Also Ec at each analysis time was higher during PR than during TR $(\mathrm{P}<0.05)$. We did not find any statistical difference change in Ec along each tested run.

\section{Head rate values}

As indicated in Table 2, the mean heart rate (HR) for PR1, PR2, and PR3 was significantly greater $(\mathrm{P}<$ 0.05 ) than for TR1, TR2, and TR3, respectively. Also HR values recorded during both PR and TR were higher than those recorded during IR $(\mathrm{P}<0.01)$. The mean heart rate obtained during PR was significantly greater than that recorded during TR $(+4 \%, \mathrm{P}<0.05)$ and IR $(+13 \%, \mathrm{P}<0.01)$. Mean $\mathrm{HR}$ recorded during TR was significantly greater than IR value $(+10 \%, \mathrm{P}<0.01)$.

\section{Analysis of EMG}

Dynamic contractions

Fig. 2 shows the variations of the integrated EMG signal expressed with regard to burst duration 
(IEMG flow) during 2 min of running (triathlon run TR, prolonged PR and isolated run IR). Mean values (7 subjects) recorded during PR2 (18-20') and PR3 (40-42') were significantly greater compared with the mean $\mathrm{PR} 1$ value $(\mathrm{P}<0.05$ and $\mathrm{P}<0.01$, respectively).

\section{Isometric contractions}

As indicated in Fig.3 a, signal amplitude (RMS) was significantly greater during all the $\mathrm{PR}(\mathrm{P}<0.01)$ in comparison with the reference value. Moreover, RMS values obtained during TR were significantly greater $(\mathrm{P}<0.05)$ than the reference value recorded before the trial. Results of MPF values for PR indicated a significant decrease for PR1, PR2, and PR3 ( $P<0.05, \mathrm{P}<0.05$, and $\mathrm{P}<0.01$, respectively) compared with the reference value recorded before the start of the trial (Fig. 3b). Moreover, results of MPF values for TR indicate a significant decrease compared with the initial value $(\mathrm{P}<0.05)$ while MPF values recorded in IR1 show a significant increase $(\mathrm{P}<0.05)$ compared with the initial value. Fig. 4 represents the alterations of the power spectrum of the EMG signal recorded on the vastus lateralis muscle for one triathlete. This triathlete was representative of the population tested during an isometric contraction of $4 \mathrm{sec}$ knee extension. Spectrums shown in this figure indicate the different frequencies obtained before and after the prolonged run which induced the most significant difference as shown in Fig. 3b.

\section{Rating of perceived exertion}

All ratings of perceived exertion values (RPE) are reported in Table 3. RPE values for TR obtained during the last isometric contraction, immediately after TR3, were significantly higher in comparison with IR values and the initial value obtained before the triathlon trial $(\mathrm{P}<0.01)$. RPE values after TR3 were significantly lower versus RPE values obtained after MR3 $(\mathrm{P}<0.05)$. Also RPE values after PR3 were significantly higher compared to RPE values after $1 \mathrm{R} 3$ and the initial RPE values recorded before the prolonged run $(P<0.01)$. RPE values after $1 R 3$ were significantly higher than RPE values obtained before the trial.

\section{Discussion}

The first observation of the present study was the increase in the integrated electromyographic flow (QiEMG) over the course of a prolonged run (PR) lasting $2 \mathrm{~h} 15 \mathrm{~min}$. In addition the results confirm that both a $2 \mathrm{~h} 15 \mathrm{~min}$ PR and triathlon event (TR) result in a significant increase in the energy cost of running (Ec) during the final phase of each event compared to an isolated run (IR: $26 \mathrm{~m}^{10} \mathrm{x} \mathrm{min}^{-1} \mathrm{x}$ $\mathrm{km}^{-1}, \mathrm{P}<0.01$ and $7 \mathrm{~m} 10_{2} \times \min ^{-1} \mathrm{x} \mathrm{km}^{-1}, \mathrm{P}<0.05$, respectively; see Table 2). Moreover, there was also a higher $\mathrm{Cr}$ during the run portion of an "Olympic Triathlon" compared with an isolated run $(\mathrm{P}<$ $0.05)$. It is noteworthy that the energy cost of the TR, PR, and IR remained constant throughout each trial (Table 2), and these values are in close agreement with those obtained in studies involving prolonged running $[32,36]$ or an overground triathlon $[14,15]$. Consequently both single- and threediscipline prolonged endurance exercise result in a decreased running economy compared to an isolated run at the same speed. The results of our experiment confirm also the decrease in running economy that occurred during a prolonged run (i.e. $2 \mathrm{~h} 15 \mathrm{~min}$ ) in comparison with an isolated run (i.e. $45 \mathrm{~min}$ ) for a similar running speed.

However, one interesting finding of this experiment is that the magnitude of changes in EMG variables under non-fatiguing (IR) and fatiguing trials (PR, TR) tended to be different. Williams et al. [35] suggested that runners did not clearly modify their running mechanics with fatigue but instead hypothesized that modifications of the patterns of motor unit recruitment could be at the beginning of a fatigue state during running. For all subjects in our study a number of EMG variables were significantly altered by the prolonged exercise.

The QiEMG of the vastus lateralis (VL) muscle was significantly higher after the $1 \mathrm{~h} 50 \mathrm{~min}$ (PR2) and $2 \mathrm{~h} 10$ min (PR3) portions of the prolonged run than at the $1 \mathrm{~h} 30$ min mark (PR1, P $<0.05$; Fig. 2 and $\mathrm{P}<0.01$, Fig. 2, respectively). There was no observed change in QiEMG during the length of the TR or IR. Interestingly the shift in QiEMG during the latter stages of the PR was not associated with a 
significant increase in the energy cost of running. Accordingly the triathletes who were not as well trained as the specialist runner experienced greater changes in their neuromuscular coordination at the end of endurance running exercise in comparison with the specialist runner. This neuromuscular alteration has been recently shown for a triathlete population after an Olympic triathlon and a marathon [23]. This study emphasized that the rise of the center of gravity of the counter-movement-jump (CMJ) was significantly lower after the marathon $(-12 \mathrm{~cm})$ than after the triathlon $(-2.5 \mathrm{~cm})$. Kinetic analysis of the CMJ showed changes during the flexion phase where the quadriceps act in part eccentrically. More eccentric contractions and mechanical constraints during the marathon (or prolonged run) may explain both the greater alteration to jump performance after the marathon [23] and the elevated QiEMG values obtained on the VL in the prolonged run of the present study. Some common factors may be expected to support this specific type of exercise. In addition structural damage has been observed after a marathon [12,34] and in exercices in which eccentric actions dominate [10], suggesting an impairment of the muscle fibre function. A muscular functioning failure may be expected after a $2 \mathrm{~h} 15 \mathrm{~min}$ run; an increased activation of the motor units (MU) of the VL may further be speculated to result from an increased reliance on the fast-twitch muscle fibres at the end of the run and/or an increase of MU discharge since the start of the prolonged run. The integrated EMG increase and the MPF of the power spectrum density function decrease were previously demonstrated for brachioradialis muscle and biceps brachii activity [11]. The results of this study suggested that in the present study a specific role of compensatory activation of other vastus lateralis agonist muscle such as the rectus femoris muscle could be observed. Moreover, the repetitive stretching loads of a prolonged run induce ultra-structural damage which might be associated with an hyperpermeability of the muscular cell [24] and with reduced ability of the muscular tissue to contract [12]. In this framework the more elevated QiEMG recorded at the end of PR vs. TR could be partly representative of the contractile properties modifications. This is partly due to the repeated eccentric loading demonstrated to result in an increased level of neural activation of the muscle at a given low level tension [19].

Analysis of surface EMG activity has been used increasingly to study muscle fatigue [8]. It has been found that during a fatiguing submaximal contraction the power spectrum of the surface EMG (MPF) shows a linear shift to lower frequencies [1]. Moreover, an increase in EMG amplitude (RMS) with time has been associated with prolonged submaximal muscle contraction [1]. To provide systematic information of muscle activation, a standard isometric contraction of knee extensors muscles (i.e. VL) was performed on three different occasions (start, middle, end of testing sessions) during PR, TR, and IR. These standard isometric tests were carried out at $35 \%$ of maximal voluntary contraction (MVC), supposing this level of contraction to be high enough to be sensitive to prior run exertion and low enough to be sustained for $4 \mathrm{sec}$ without generating an extra fatigue level and not occluding muscle blood flow. It was then assumed that all recorded EMG data at this force level during a static contraction could be an indicator of the fatigue state generated by the various dynamic exercises of this study (triathlon, prolonged run, isolated run). The increase of QiEMG during the final phase of PR (dynamic contraction) is associated with a significant elevated value of EMG amplitude (isometric contraction, Fig. 3a) and a significant shift of MPF towards lower frequencies (isometric contraction, Fig. 3b) in comparison with the reference value (e.g. in Fig. 4). It is well documented that the power density spectrum of an EMG signal is compressed toward lower frequencies as a sustained contraction progresses $[18,26]$.

According to the present study the shift of MPF towards lower frequencies and the increase in EMG amplitude were more marked during PR than TR. Although we have not proposed a time-limit for a submaximal static contraction as in many studies $[8,18,26]$, we suggest that isometric EMG data may indirectly reflect the variation in the muscle generated during all dynamic exercises. The isometric test therefore reveals some additional complementary information regarding the neuromuscular state during the final phase of the different runs. Nicol et al. [29] have previously shown that pre-marathon iEMG activity values were elevated by $34 \%$ following the competitive marathon run. In accordance with this we have found respective increases in EMG amplitude across the PR and TR of 22 and 12\% (Fig. 3 a). These results were linked to the mean value obtained on the scale of perceived effort [5] (Table 3): 14.6 and 11.2 points for post-prolonged run and post-triathlon, respectively. Both the increase in EMG amplitude and decrease in MPF values during PR were associated with the most elevated rating of perceived exertion (RPE) as has been confirmed in an earlier study using a subjective approach to a fatigue state [31]. Although we assumed that the additional EMG testing of an isometric contraction (of 
short duration and at $35 \% \mathrm{MVC}$ ) during the runs was not enough to increase muscle fatigue level significantly, we hypothesized that only the cellular alterations which appear at the end of PR and TR might have influenced the present increase of RPE obtained in post-marathon and post-triathlon.

In conclusion, the results of the present investigation confirm the increase of the energy cost of running during the final phase of a prolonged run and a treadmill based triathlon run. One particularly important feature was that a $2 \mathrm{~h} 15 \mathrm{~min}$ prolonged run induced greater neuromuscular alterations, identified by an increase in the integrated EMG flow of the vastus lateralis muscle, than a triathlon lasting the same amount of time but combining 3 disciplines (viz. swimming, cycling, and running). Thus, by combining three different activities into a continuous event, the triathlon appears to induce less muscle alteration as illustrated by the stability in iEMG flow recorded during the run portion. The observed change in running economy could not be related to an isolated EMG factor such as the muscle activation of the vastus lateralis. In addition it is suggested that the rating of perceived exertion recorded during isometric contractions is a good indice to approach the level of fatigue during different modalities of prolonged exercices.

\section{Acknowledgements}

The authors gratefully acknowledge Matt Spencer (Western Australia Institut of Sport) and Darren Smith (Sport Scientist, Queensland Triathlon) for their active support during the corrections of this manuscript.

\section{References}

${ }^{1}$ Arendt-Nielsen L, Mills RK. Muscle fibre conduction velocity, mean power frequency, mean EMG voltage and force during submaximal fatiguing contractions of human quadriceps. Eur J Appl Physiol 1988; $58: 20-25$

${ }^{2}$ Astrand P0, Rhyming I. A nomogram for calculation of aerobic capacity (physical fitness) from pulse rate during submaximal work. J Appl Physiol 1954; 7: 218 - 222

${ }^{3}$ Bigland-Ritchie B, Woods JJ. Changes in muscle contractile properties and neural control during human muscular fatigue. Muscle Nerve 1984; 7: 691 - 699

${ }^{4}$ Boone T, Kreider RB. Bicycle exercise before running: effect on performance. Ann Sports Med 1986; 3: $25-29$

${ }^{5}$ Borg GAV. Perceived exertion as an indicator of somatic stress. Scand J Rehab Med 1970; 2: 92 - 98

${ }^{6}$ Brueckner JC, Atchou G, Capelli C, Duvallet A, Barrault D, Joussellin E, Rieu M, di Prampero PE. The energy cost of running increases with the distance covered. Eur J Appl Physiol 1991; 62: 385 389

${ }^{7}$ Davies CTM, Thompson MW. Physiological responses to prolonged exercise in ultramarathon athletes. J Appl Physiol 1986; 61: 611- 617

${ }^{8}$ De Luca CJ. Myoelectrical manifestations of localized muscular fatigue in humans. Crit Rev Biomed Eng 1984; 11: 251 - 279

${ }^{9}$ Di Prampero PE. The energy cost of human locomotion on land and in water. Int J Sports Med 1986; 7: $55-72$

${ }^{10}$ Fridén J, Sjöström M, Ekblom B. A morphological study of delayed muscle soreness. Experientia 1981; 37: 506 - 507 
${ }^{11}$ Gamet D, Maton B. The fatigability of two muscles in human isometric voluntary submaximal contraction: an EMG study. Assessment of muscular fatigue by means of surface EMG. Eur J Appl Physiol 1989; 58: 361 - 368

${ }^{12}$ Gunderson HM, Parliman JA, Parker JA, Bell G. Membrane permeability changes as a fatigue factor in marathon runners. In: Knuttgen HG et al. (eds). The Biochemistry of Exercise. Champaign, IL: Human Kinetics Publishers, 1983; 13: 877 - 881

${ }^{13}$ Guézennec CY, Giaoui M, Voignier JP, Legrand H, Fournier E. Evolution des taux plasmatiques des LDH (lacticodeshydrogénase), CPK (créatine phosphokinase) et de la myoglobine à l'issue d'une course de $100 \mathrm{~km}$ et d'un triathlon. Science \& Sports 1986; 1: 255 - 263

${ }^{14}$ Guézennec CY, Vallier JM, Bigard AX, Durey A. Increase in energy cost of running at the end of a triathlon. Eur J Appl Physiol 1996; 73: 440- 445

${ }^{15}$ Hausswirth C, Bigard AX, Berthelot M, Guézennec CY. Variability in energy cost of running at the end of a triathlon and a marathon. Int J Sports Med 1996; 17: 574 - 581

${ }^{16}$ Hausswirth C, Bigard AX, Guézennec CY. Relationships between energy cost of running and running mechanics occurring at the end of a triathlon and a marathon. Int J Sports Med 1997; 18: 330 - 339

${ }^{17}$ Heise GD, Morgan DW, Hough H, Craib M. Relationships between running economy and temporal EMG characteristics of bi-articular leg muscles. Int J Sports Med 1996; 17: 128 -133

${ }^{18}$ Kadefors R, Kaiser E, Petersen I. Dynamic spectrum analysis of myo-potentials with special reference to muscle fatigue. Electromyography 1968; 8: 8 - 39

${ }^{19}$ Komi PV, Viitasalo JT. Changes in motor unit activity and metabolism in human skeletal muscle during and after repeated eccentric and concentric contractions. Acta Physiol Scand 1977; 100: 246254

${ }^{20}$ Komi PV, Tesch P. EMG frequency spectrum, muscle structure and fatigue during contractions in man. Eur J Appl Physiol 1979; 42: 41 -50

${ }^{21}$ Kreider RB, Cundiff DE, Hammet JB, Cortes CW, William KW. Effects of cycling on running performance in triathletes. Annals Sports Med 1988; 4: 220 - 225

${ }^{22}$ Kwatny E, Thomas DH, Kwatny HG. An application of signal processing techniques to the study of myoelectric signais. IEEE Trans Biomed Eng 1970; 17: 303 -312

${ }^{23}$ Lepers R, Hausswirth C. Altérations des performances neuromusculaires après un exercice physique prolongé: analyse comparée du triathlon et du marathon. Science \& Motricité 1988; 34: 37 - 43

${ }^{24}$ Magazanik A, Shapiro T, Meytes D, Meytes I. Enzyme blood levels and water balance during a marathon race. J Appl Physiol 1974; 36: 214-217

${ }^{25}$ Medbø Jl, Mohn AC, Tabata I, Bahr R, Vaage 0, Sejersted OM. Anaerobic capacity determined by maximal accumulated $0_{2}$ deficit. J Appl Physiol 1988; 64: 50-60

${ }^{26}$ Mills KS. Power spectral analysis of electromyogram and compound muscle action potentiel during muscle fatigue and recovery. J Physiol 1982; 36: 362 - 401

${ }^{27}$ Montain SJ, Coyle EF. Influence of graded dehydration on hyperthermia and cardiovascular drift during exercise. J Appl Physiol 1992; 73: 1340-1350 
${ }^{28}$ Moritani T, Oddson L, Thorstensson A. Electromyographic evidence of selective fatigue during the eccentric phase of stretchshortening cycle in man. Eur J Appl Physiol 1990; 60: 425 -429

${ }^{29}$ Nicol C, Komi PV, Marconnet P. Fatigue effects of marathon running on neuromuscular performance: changes in force, integrated electromyographic activity and endurance capacity. Scand J Med Sci Sports 1991; 1: 18 - 24

${ }^{30}$ O'Toole ML, Hiller WDB, Crosby LO, Douglas PS. The ultraendurance triathlete: a physiological profile. Med Sci Sports Exerc 1987; 19: 45-50

${ }^{31}$ Setruk D, Fery Y, Ferry A, Rieu M. Perception subjective de la fatigue musculaire: utilisation de l'échelle de Borg. Science \& Sports 1995; 10: 209 - 210

${ }^{32}$ Sproule J. Running economy deteriorates following 60 min of exercise at $80 \% \mathrm{VO}_{2}$ max. Eur J Appl Physiol 1998; 77: 366 - 371

${ }^{33}$ Viitasalo JT, Komi PV, Jacobs 1, Karlsson J. Effects of prolonged cross-country skiing on neuromuscular performance. In: Komi PV (ed). Exercise and Sport Biology International Series on Sport Sciences. Champaign, IL: Human Kinetic Publishers, 1982; 12: 191 -198

${ }^{34}$ Wahrol MJ, Siegel AJ, Evans WJ, Silverman LM. Skeletal muscle in-jury and repair in marathon runners after competition. Am J Pathol 1985; 118: 331- 339

35 Williams KR. Biomechanics in distance running. In: Grabiner MD (ed). Current Issues in Biomechanics. Champaign, IL: Human Kinetic Publishers, 1993: 17

${ }^{36} \mathrm{Xu} \mathrm{F}$, Montgomery DL. Effect of prolonged exercise at 65 and $80 \% \mathrm{VO}_{2}$ max on running economy. Int J Sports Med 1995; 16: $309-315$ 
Table 1 Physical and physiological characteristics of the subjects. Values are means $\pm \mathrm{SD} . \mathrm{VO}_{2} \max$, maximal oxygen uptake; MAS, maximal aerobic speed

\begin{tabular}{|c|c|c|c|c|c|}
\hline Age (yrs) & Body mass (kg) & Height (cm) & $\begin{array}{c}\mathrm{VO2max}(\mathrm{ml} x \\
\left.\min ^{-1} \mathrm{x} \mathrm{kg}^{-1}\right)\end{array}$ & 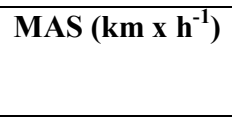 & $\begin{array}{c}\text { Average training } \\
\text { distance per } \\
\text { week }(\mathrm{km}) \\
\end{array}$ \\
\hline $31 \pm 5$ & $72.2 \pm 2.4$ & $175.1 \pm 3.1$ & $66.8 \pm 5$ & $18.4 \pm 1.5$ & $\begin{array}{l}6.2 \text { swim } \\
155 \text { bike } \\
65 \text { run } \\
\end{array}$ \\
\hline
\end{tabular}

Table 2 Changes in the energy colt of running $(\mathrm{Cr})$ and heart rate (HR) obtained during the Triathlon Run (TR), the Marathon Run (PR), and the Isolated Run (IR) (i.e. 45 min of the final run for each testing session). Values are means $( \pm \mathrm{SD})$

\begin{tabular}{|c|c|c|c|c|c|c|c|c|c|c|}
\hline & \multicolumn{3}{|c|}{ Triathlon run } & \multicolumn{3}{|c|}{ Prolonged run } & \multicolumn{3}{|c|}{ Isolated run } & \multirow{2}{*}{$\begin{array}{l}\text { ANOVA } \\
\text { Exercise } \\
\text { Time }\end{array}$} \\
\hline & TR1 & TR2 & TR3 & PR1 & PR2 & PR3 & IR1 & IR2 & IR3 & \\
\hline $\begin{array}{l}\text { Energy } \\
\text { Cost of } \\
\text { running, } \\
\text { Ec }(\mathrm{ml} \\
x \quad \min ^{-1} \\
\left.x \mathrm{~kg}^{-1}\right)\end{array}$ & $\begin{array}{l}219.6 \pm \\
12.6^{\mathrm{b}, \mathrm{c}}\end{array}$ & $\begin{array}{l}220.1 \pm \\
14.6^{b, c}\end{array}$ & $\begin{array}{l}220.9^{ \pm} \\
16.7^{\mathrm{b}}\end{array}$ & $\begin{array}{l}226.6 \pm \\
17.3^{\mathrm{b}}\end{array}$ & $\begin{array}{l}227.4 \pm \\
18.2^{\mathrm{b}}\end{array}$ & $\begin{array}{l}228.3^{ \pm} \\
14.6^{\mathrm{b}}\end{array}$ & $\begin{array}{l}200.9 \pm \\
11.5\end{array}$ & $\begin{array}{l}204.8 \pm \\
13.5\end{array}$ & $\begin{array}{l}204.4 \pm \\
15.3\end{array}$ & $\begin{array}{l}\mathrm{P}<0.05 \\
\text { NS }\end{array}$ \\
\hline $\begin{array}{l}\text { Heart } \\
\text { rate, } \\
\text { HR } \\
\text { (beats x } \\
\text { min }^{-1} \text { ) } \\
\end{array}$ & $\begin{array}{l}163 \pm \\
16.5^{\mathrm{b}, \mathrm{c}}\end{array}$ & $\begin{array}{l}168+ \\
17.6^{\mathrm{b}, \mathrm{c}}\end{array}$ & $\begin{array}{l}171 \pm \\
14.3^{b, c}\end{array}$ & $\begin{array}{l}168 \pm \\
16.8^{b}\end{array}$ & $\begin{array}{l}175+ \\
15.1^{\mathrm{b}}\end{array}$ & $\begin{array}{l}179+ \\
16.2^{\mathrm{b}}\end{array}$ & $\begin{array}{l}147+ \\
13.3\end{array}$ & $\begin{array}{l}151 \pm \\
13.1\end{array}$ & $\begin{array}{l}154 \pm \\
13.5\end{array}$ & $\begin{array}{l}\mathrm{P}<0.05 \\
\mathrm{NS}\end{array}$ \\
\hline
\end{tabular}

Significantly different from IR group, ${ }^{\mathrm{a}}(\mathrm{P}<0.05),{ }^{\mathrm{b}}(\mathrm{P}<0.01)$. Significantly different from PR group, ${ }^{\mathrm{c}}$ $(\mathrm{P}<0.05),{ }^{\mathrm{d}}(\mathrm{P}<0.01)$.

TR1: start of triathlon run (2-5 min, period 1); TR2: middle of triathlon run (15-22 min, period 2); TR3: end of triathlon run (35-42 min, period 3)

PR1: start of prolonged run (2-5 min, period 1); PR2: middle of prolonged run (15-22 min, period 2); PR3: end of prolonged run (35-42 min, period 3) IR1: start of isolated run (2-5 min, period 1); IR2: middle of isolated run (15-22 min, period 2); IR3: end of isolated run (35-42 min, period 3) 
Table 3 Changes in effort perceived values obtained after isometric contraction for knee extension sustained during $4 \mathrm{sec}$ at $35 \% \mathrm{MVC}_{80}$. Values were recorded before and after each trial according to the Borg's scale DP20 (Borg 1970)

\begin{tabular}{|l|c|c|c|c|}
\hline \multicolumn{1}{|c|}{ Groups } & \multicolumn{2}{c|}{ Effort perceived Before } & \multicolumn{2}{c|}{ Effort perceived After } \\
\hline & Mean & SD & Mean & SD \\
\hline Triathlon run (TR) & 6.2 & \pm 0.2 & $11.2^{* *, S, f}$ & \pm 1.1 \\
\hline Prolonged run (PR) & 6.5 & \pm 0.1 & $14.6^{* *, t}$ & \pm 1.4 \\
\hline Isolated run (IR) & 6.4 & \pm 0.2 & $7.1^{\text {SS, }}$ & \pm 0.9 \\
\hline ANOVA & & & & \\
\hline Exercise & NS & & $\mathrm{P}<0.05$ & \\
\hline Time & & & $\mathrm{NS}$ & \\
\hline Interaction & & & $\mathrm{P}<0.05$ & \\
\hline
\end{tabular}

Significantly different from IR group, $*(\mathrm{P}<0.05, * *(\mathrm{P}<0.01)$. Significantly different from $\mathrm{PR}$ group, ${ }^{\$}(P<0.05),{ }^{\$}(P<0.01)$. Significantly different from reference values (before), ${ }^{\mathfrak{f}}(\mathrm{P}<0.01)$.

Fig. 1 Experimental protocol.

TRIATHLON (2H15)

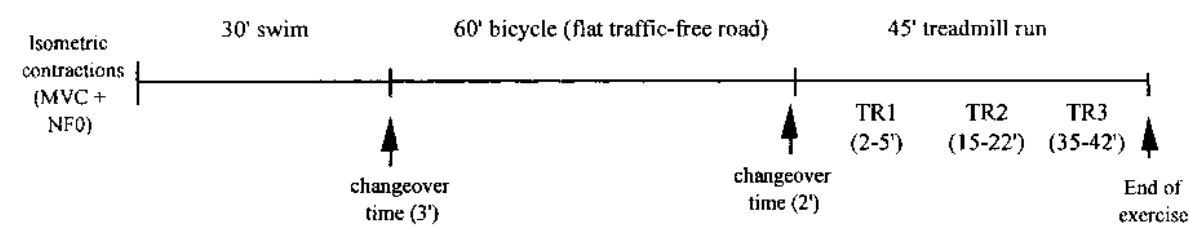

PROLONGED RUN (2H15)

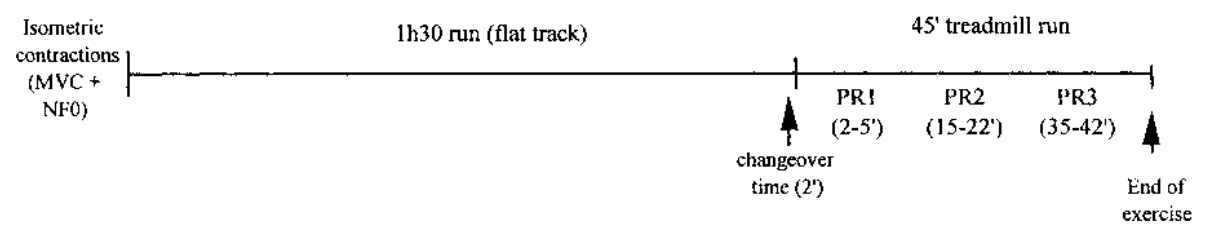

ISOLATED RUN (45')

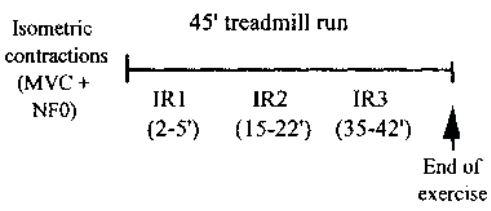


Fig.2 Changes in integrated EMG signal expressed with regard to burst duration (QiEMG flow) during 2 min of running (triathlon run, prolonged run and isolated run).

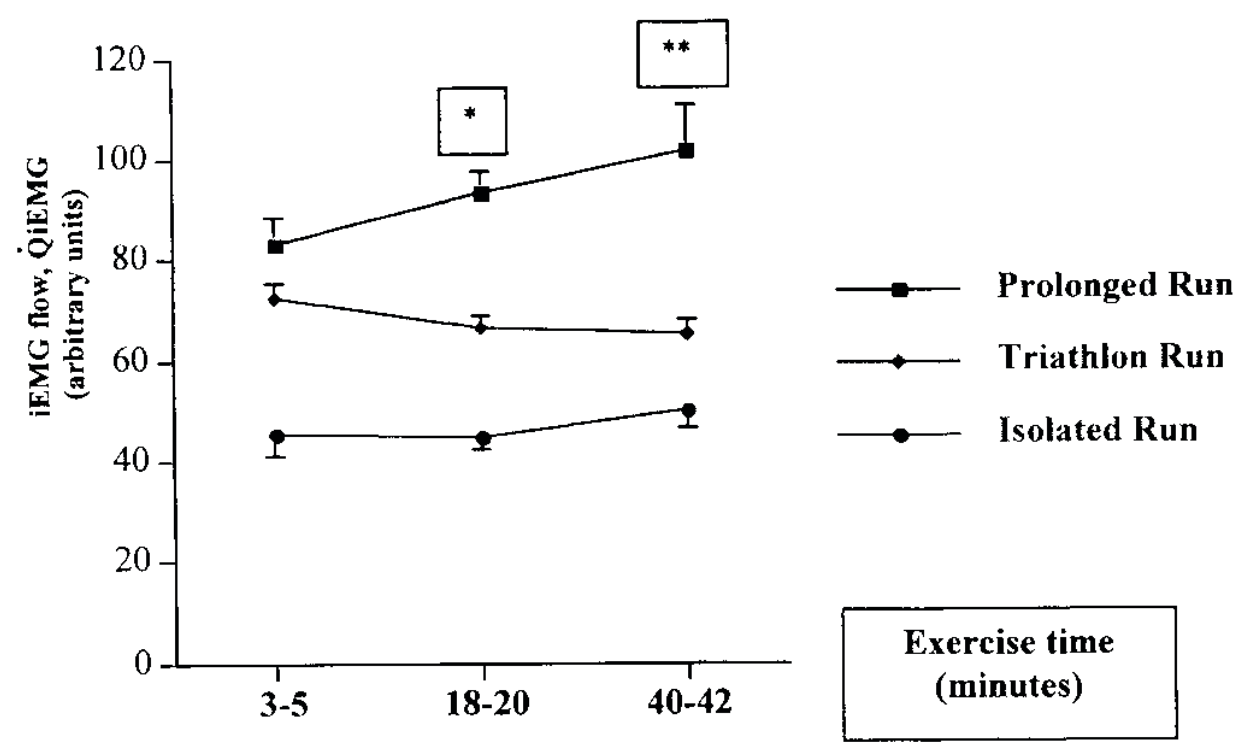

Fig.3a Changes in signal amplitude (RMS) obtained for 3 seconds of isometric contraction of knee extension; all values are means $( \pm \mathrm{SD})$ and recorded during the triathlon run, the prolonged run, and the isolated run. For each trial values were compared with the reference value (i.e. before exercise, 100\%).

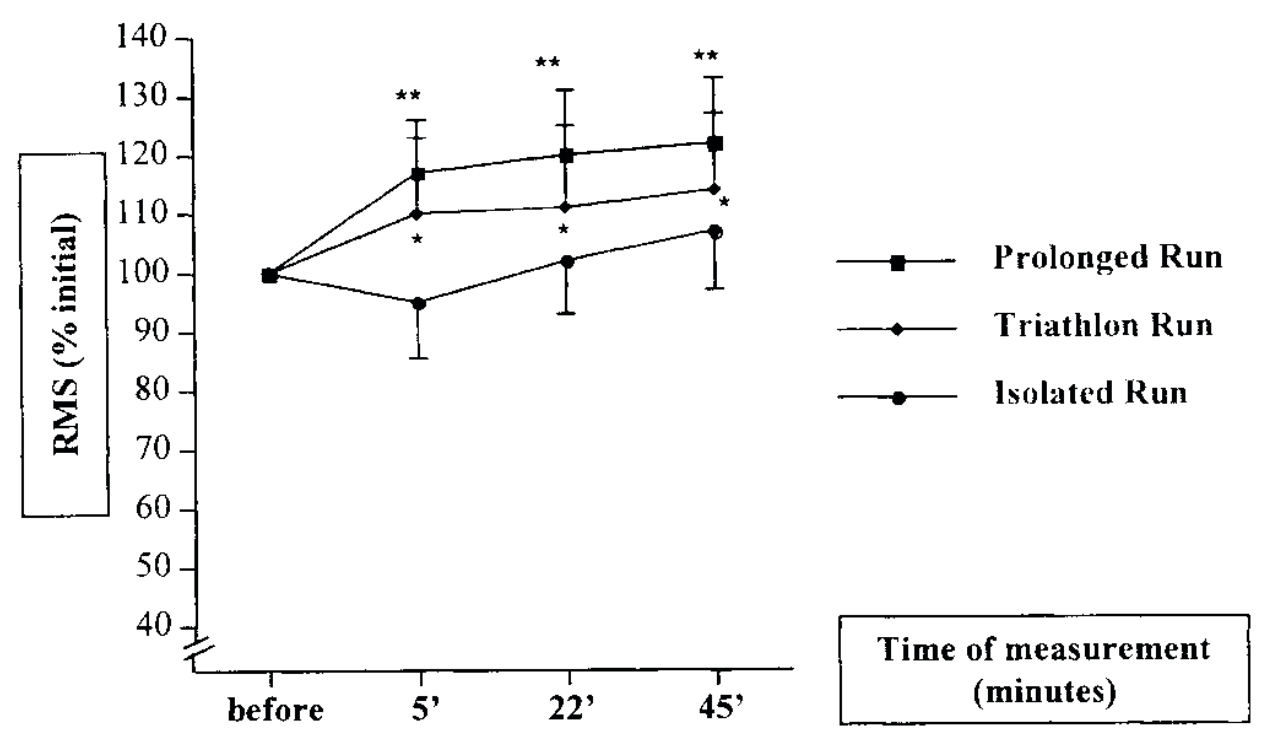


Fig.3b Changes in mean power frequency (MPF) obtained for 3 seconds of isometric contraction of knee extension; all values are means $( \pm \mathrm{SD})$ and recorded during the triathlon run, the prolonged run, and the isolated run. For each trial values were compared with the reference value (i.e. before exercise, $100 \%)$.

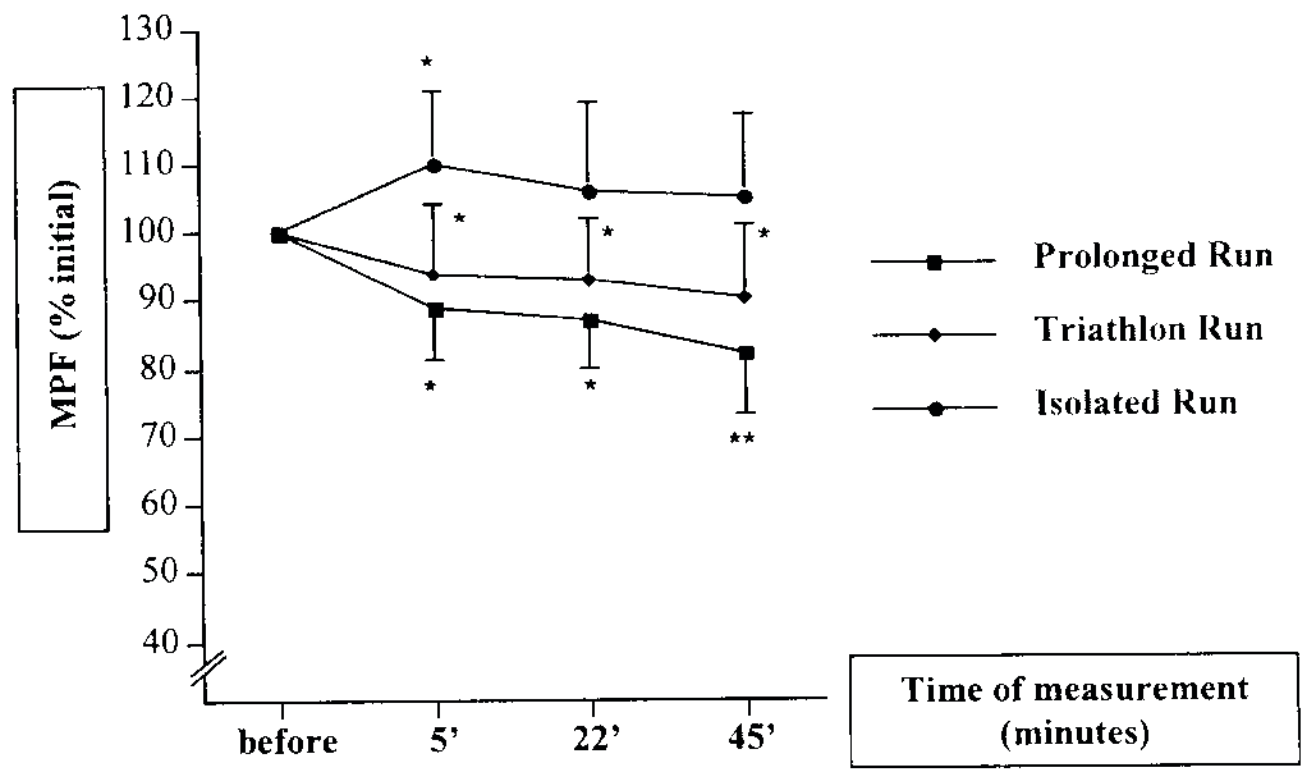

Fig. 4 Modifications of the power spectrum of the EMG signal recorded for the population tested (mean values, 7 subjects) during an isometric contraction of $3 \mathrm{sec}$ of knee extension. Spectra shown on the above represent the different frequencies obtained before (left) and alter the prolonged run (right).

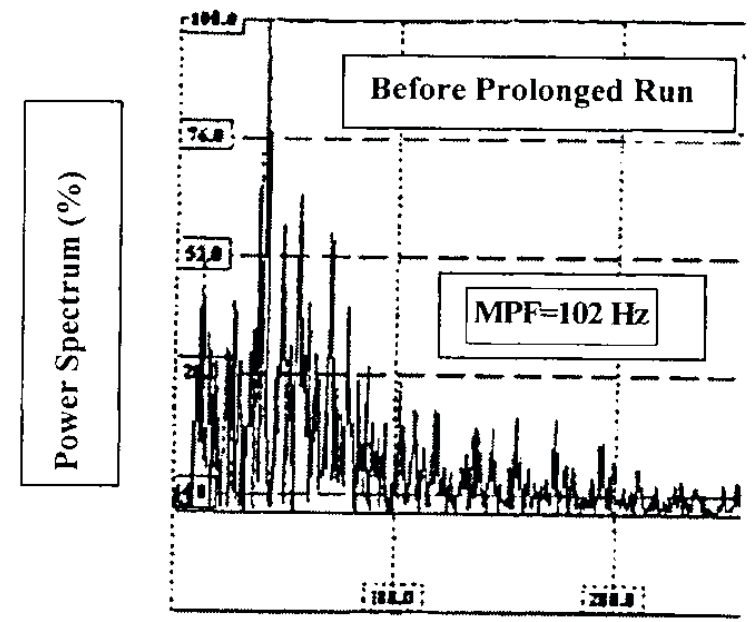

Frequencies $(\mathrm{Hz})$

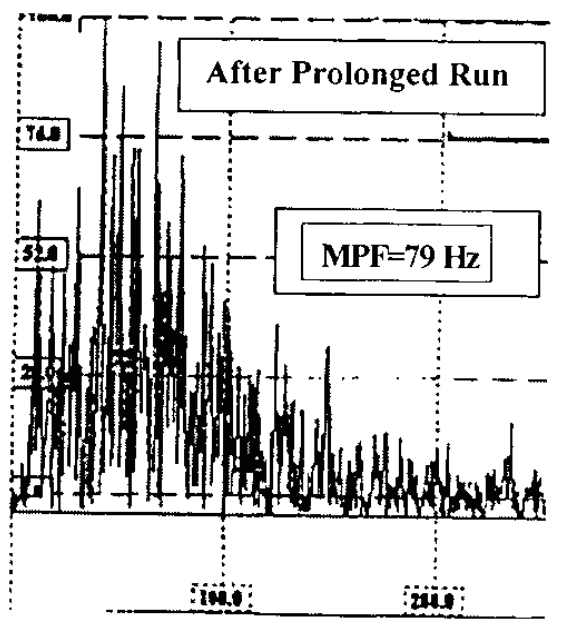

Frequencies $(\mathrm{Hz})$ 